\title{
Retraction Note to: Lupeol enhances inhibitory effect of 5-fluorouracil on human gastric carcinoma cells
}

\author{
Yan Liu ${ }^{1} \cdot$ Tingting $\mathrm{Bi}^{2}$ - Wei Dai ${ }^{1}$. Gang Wang ${ }^{1} \cdot$ Liqiang Qian $^{1}$ - Genhai Shen ${ }^{1} \cdot$ Quangen Gao ${ }^{1}$
}

Published online: 13 August 2021

(c) Springer-Verlag GmbH Germany, part of Springer Nature 2021

\section{Retraction Note to: Naunyn-Schmiedeberg's Arch Pharmacol (2016) 389:477-484 https://doi.org/10.1007/s00210-016-1221-y}

The Editor-in-Chief has retracted this article at the request of the first author. This article shows significant overlap with previously published articles from the same authors [1,2]. Additionally, concerns were raised regarding Figures $4 \mathrm{a}$ and $5 b$. The first author has stated errors occurred in the process of data processing and the selection of the figures. The first author also stated that some of the data could not be recovered. The Editor-in-Chief therefore no longer has confidence in the reliability of the data reported in the article.

All authors agree to this retraction.

The original article can be found online at https://doi.org/10.1007/ s00210-016-1221-y.

Quangen Gao

wjyygqg@sohu.com; wjyysgh@163.com

1 Department of General Surgery, Wujiang No. 1 People's Hospital, Suzhou 215200, China

2 Department of Geriatric Ward, Wujiang No. 1 People's Hospital, Suzhou 215200, China

\section{References}

1. Liu Y, Bi T, Dai W et al (2016) Oxymatrine synergistically enhances the inhibitory effect of 5-fluorouracil on hepatocellular carcinoma in vitro and in vivo. Tumor Biol 37:7589-7597. https:// doi.org/10.1007/s13277-015-4642-1

2. Liu Y, Bi T, Wang G et al (2015) Lupeol inhibits proliferation and induces apoptosis of human pancreatic cancer PCNA-1 cells through AKT/ERK pathways. Naunyn-Schmiedeberg's Arch Pharmacol 388:295-304. https://doi.org/10.1007/s00210-014-1071-4

Publisher's note Springer Nature remains neutral with regard to jurisdictional claims in published maps and institutional affiliations. 